United Nations Conference on Trade and Development (2002) See http:// www.unctad.org/

World Bank (2005) See http://web.worldbank.org/

World Bank (2006) World Development Indicators Database, April 2006, at http://devdata.worldbank.org/
World Health Organization (2005) Lao People's Democratic Republic. In Mental Health Atlas 2005. See http://globalatlas.who.int/globalatlas/ predefinedReports/MentalHealth/Files/LA_Mental_Health_Profile.pdf

World Health Organization (2006) Lao People's Democratic Republic, at http://www.who.int/countries/lao/

\title{
Psychiatric morbidity among patients on haemodialysis in the Mosul district of Iraq
}

\author{
Hellme Najim MBChB Mosul DPM London MRCPsych ${ }^{1}$, Emad Al-Badrani MBChB Mosul ${ }^{2}$ \\ and Khalid Omar Sultan MBChB Mosul MD ${ }^{3}$
}

${ }^{1}$ Consultant Psychiatrist, Mental Health Unit, Basildon Hospital, Basildon, Essex SS16 5NL, UK, email hellmenajim@yahoo.co.uk ${ }^{2}$ Consultant in Renal Medicine, Department of Medicine, Mosul College of Medicine, Mosul, Iraq ${ }^{3}$ Consultant Physician, Mosul Teaching Hospital, Mosul, Iraq

\begin{abstract}
Datients on chronic haemodialysis experience a wide range of physical and psychological stresses. The specific sources of stress include: loss or threatened loss of possessions; relationship problems (e.g. staff-patient relationships, changed roles within the family); restrictions related to physical health status and the dialysis regimen; loss of body function and impaired body image; increased dependency and aggression; the threat of death; impairment of vocational function and financial security; and decreased participation in leisure, social and community activities (Phipps \& Turkington, 2001). A review of psychological maladjustment in patients on haemodialysis found that about $55 \%$ exhibited significant emotional distress, a prevalence three to five times that found in the general population (Aghanwa \& Morakinyo, 1997). The present study aimed to ascertain the prevalence of psychiatric morbidity among patients attending a renal dialysis unit in Mosul, Iraq.
\end{abstract}

\section{Patients and method}

The renal dialysis unit in Mosul comprises a 12-bed ward with two British graduate consultants and one Arab Board graduate. Haemodialysis and peritonial dialysis are carried out on an in- and out-patient basis. The unit serves the Mosul district, which has an urban population of about 1 million.

A standardised schedule (the Crown-Crisp Experiential Index, CCEI), as translated and validated for use in Iraqi culture by Maghazaji et al (1982), was administered to all patients who attended the unit over a 6 -month period. It is a self-rated, 48-item questionnaire with six scales (anxiety, phobia, obsession, somatic symptoms, depression and hysteria). Patients who were critically ill or who refused to participate were excluded. The questionnaire was also administered over the same period to an age- and gender-matched sample of healthy nursing staff on the unit.

For the statistical analyses, $t$-test, analysis of variance (ANOVA) and regression were used. Because of the small size of the sample, it was decided to set significance at the $10 \%$ level.

\section{Results}

A total of 62 patients attended the unit during the study period; of these, two were too ill to complete the questionnaire, seven refused to participate and two withdrew their consent at a later stage. There were more women than men in the sample (55\%). The majority of participants were under 45 year of age (88\%). Approximately half $(49 \%)$ came from urban areas. Hypertension was the most common cause of renal failure (45\%), followed by renal calculi $(24 \%)$ and glomerulonephritis (20\%); other causes (12\%) were

Table 1 Mean (s.d.) scores on the CCEI scales of patients and controls

\begin{tabular}{|c|c|c|c|c|}
\hline Scale & $\begin{array}{l}\text { Patients } \\
(n=51)\end{array}$ & $\begin{array}{l}\text { Controls } \\
(n=50)\end{array}$ & $t$ & $P$ \\
\hline Anxiety & $7.9(3.1)$ & $5.1(3.1)$ & 8.00 & $>0.1$ \\
\hline Phobia & $4.7(2.7)$ & $2.9(2.2)$ & 5.00 & $>0.01$ \\
\hline Obsession & $8.1(2.9)$ & $5.8(3.1)$ & 4.03 & $>0.01$ \\
\hline Somatic & $7.7(3.0)$ & $3.2(2.4)$ & 8.32 & $>0.1$ \\
\hline Depression & $8.2(3.2)$ & $3.3(2.3)$ & 8.90 & $>0.1$ \\
\hline Hysteria & $5.9(2.7)$ & $7.1(3.1)$ & 2.20 & $>0.05$ \\
\hline
\end{tabular}

Table 2 Mean (s.d.) scores on the CCEI scales of male and female patients

\begin{tabular}{|c|c|c|c|c|}
\hline Scale & $\begin{array}{l}\text { Males } \\
(n=23)\end{array}$ & $\begin{array}{l}\text { Females } \\
(n=28)\end{array}$ & $t^{1}$ & $P$ \\
\hline Anxiety & $6.8(2.8)$ & $9.0(3.3)$ & 2.42 & $<0.05$ \\
\hline Phobia & $4.7(1.8)$ & 4.6 (3.5) & 2.04 & NS \\
\hline Obsession & $8.7(2.7)$ & $9.4(3.1)$ & 0.80 & NS \\
\hline Somatic & $6.7(3.5)$ & $8.6(2.5)$ & 2.09 & $<0.05$ \\
\hline Depression & $7.5(3.3)$ & $8.8(3.0)$ & 1.56 & NS \\
\hline Hysteria & $5.2(3.0)$ & $6.7(2.4)$ & 1.29 & NS \\
\hline
\end{tabular}

1. $t$-test for unpaired case, degree of freedom $\left(n_{1}+n_{2-2}\right)=43$.

NS, no statistically significant association. 
Table 3 Mean (s.d.) scores on CCEI scales of urban and rural patients

$\begin{array}{lllll}\text { Scale } & \begin{array}{l}\text { Urban } \\ (n=25)\end{array} & \begin{array}{l}\text { Rural } \\ (n=26)\end{array} & t^{1} & P \\ \text { Anxiety } & 9.1(2.8) & 6.4(3.1) & 3.04 & <0.01 \\ \text { Phobia } & 6.4(3.4) & 4.9(2.5) & 1.51 & \text { NS } \\ \text { Obsession } & 9.3(3.2) & 8.1(2.9) & 1.19 & \text { NS } \\ \text { Somatic } & 8.6(2.5) & 5.8(4.0) & 2.94 & <0.01 \\ \text { Depression } & 8.8(3.3) & 5.6(2.9) & 3.21 & <0.01 \\ \text { Hysteria } & 6.2(3.0) & 4.6(2.8) & 1.69 & \text { NS }\end{array}$

1.t $t$-test for unpaired case, degree of freedom $\left(n_{1}+n_{2-2}\right)=43$.

NS, no statistically significant association.

Table 4 Mean (s.d.) scores on the CCEI scales of patients by length of dialysis

\begin{tabular}{lllll} 
Scale & $\begin{array}{l}\text { Dialysis for } \\
\text { up to 2 years } \\
(n=30)\end{array}$ & $\begin{array}{l}\text { Dialysis for } \\
\text { more than 2 } \\
\text { years }(n=21)\end{array}$ & $t^{1}$ & $P$ \\
\hline $\begin{array}{l}\text { Anxiety } \\
\text { Phobia }\end{array}$ & $8.0(3.1)$ & $10.6(2.7)$ & 3.80 & $<0.025$ \\
Obsession & $5.1(3.0)$ & $7.5(2.8)$ & 2.83 & $<0.01$ \\
Somatic & $7.2(3.2)$ & $10.4(3.3)$ & 6.05 & $<0.01$ \\
Depression & $8.7(2.9)$ & $11.8(2.8)$ & 5.15 & $<0.01$ \\
Hysteria & $6.4(2.8)$ & $10.9(3.0)$ & 5.15 & $<0.025$ \\
\hline
\end{tabular}

1. ANOVA degrees of freedom, $v_{1}=2, v_{2}=43$.

tuberculosis of the kidney, renal tubular acidosis and Fanconi syndrome. There were no statistical differences in the distribution of these syndromes by gender.

Table 1 compares psychiatric morbidity between the control and patient groups. It shows statistically significant differences between the two groups on all six scales of the CCEI.

Table 2 presents differences in psychiatric morbidity between males and females. There were statistically significant differences on the anxiety and somatic scales, with females more affected. Table 3 presents the relationship between CCEI scores and rural $v$. urban residence. It shows that there were statistically significant differences on the anxiety, somatic and depression scales, with the urban population more affected. Table 4 presents CCEI scores in relation to duration of haemodialysis. It shows statistically significant differences on all scales, with scores proportional to the duration of dialysis. Finally, Table 5 relates CCEI scores to the aetiology of renal failure. It shows statistically significant differences on two scales, anxiety and hysteria.

\section{Discussion}

In the present study, $88 \%$ of patients were below 45 years of age, which is consistent with a haemodialysis sample from European countries in 1964-71 (Gurland et al, 1975) (thereafter the mean age of patients starting haemodialysis started to increase in Europe). There was also a slight excess of females, again consistent with the study by Gurland et al (1975), in which the female:male ratio was 1.42 .

Hypertension was the most common cause of the need for haemodialysis (45\%), which is different from studies in highincome countries; for example, only $1 \%$ of patients were undergoing dialysis as a result of hypertension in the study by Gurland et al (1975). This finding can be explained by the poor prognosis associated with other causes of renal failure in Iraq, which may result in under-representation of these diseases in the sample.

The statistically significant differences in psychiatric morbidity on all CCEI scales (Table 1) of patients compared with controls indicate that those on renal dialysis have more vulnerability to psychiatric illness, owing to the physical and psychological stress they are under, which is consistent with previous studies (Aghanwa \& Morakinyo, 1997).

There was a statistically significant gender difference on two scales: anxiety and somatic. Other studies have reported that psychiatric morbidity (neurosis) is greater in females than in males. However, in the present study, the surprising result was that scores on the hysteria scale did not differ between the genders. As men should find it easier to move around a male-dominated society, the male sample might have been disproportionately drawn from rural areas, and men in rural areas may be similar to women from urban areas in terms of their propensity to dissociation.

There was no statistically significant difference between age-groups in the present sample. This may have several explanations: first, it could be due to the relatively young age of the sample overall; second, it could be due to their relatively recent diagnosis and start on haemodialysis; and lastly, it might indicate that haemodialysis has no relationship with age and psychiatric morbidity.

There were statistically significant differences between rural and urban patients on the anxiety and depression scales. These might have been due to the exaggerated impact of the diagnosis and treatment as understood by patients from rural areas, and their fear of dealing with machines, compared with the urban population, who might be expected to be more technology oriented and more socially enlightened, and to understand better the implications of their disease and their dependence on the machine for the rest of their lives. Patients from a rural background also expressed significantly more somatic complaints and this similarly can be explained on the basis of their greater tendency than urban patients to somatise (Racy, 1980), in addition to the physical stresses of life in rural areas and difficulties of transport to town.

When the sample was divided by duration of dialysis, there were statistically significant differences on all scales. This is likely to reflect how patients come to appreciate, over time, that they are bound to machines for the rest of their lives

Table 5 Mean (s.d.) scores on the CCEI scales of patients according to the aetiology of their renal failure

\begin{tabular}{|c|c|c|c|c|c|c|}
\hline Scale & Hypertension $(n=23)$ & Glomerular nephritis $(n=10)$ & Stones $(n=12)$ & Other $(n=6)$ & $t^{1}$ & $P$ \\
\hline Anxiety & $23.0(13.8)$ & $7.4(3.7)$ & $7.9(5.1)$ & $8.6(2.3)$ & 8.14 & $<0.005$ \\
\hline Phobia & $5.9(2.3)$ & $5.1(3.5)$ & $5.8(3.0)$ & $4.9(2.9)$ & 0.39 & NS \\
\hline Obsession & $8.8(2.5)$ & $9.0(2.8)$ & $8.0(2.4)$ & $10.8(4.1)$ & 1.40 & NS \\
\hline Somatic & $8.4(2.9)$ & $6.7(2.9)$ & $7.6(4.0)$ & $6.3(3.8)$ & 1.09 & NS \\
\hline Depression & $7.7(3.0)$ & $6.4(3.1)$ & $8.1(3.9)$ & $9.4(3.5)$ & 1.08 & NS \\
\hline Hysteria & $5.5(2.2)$ & $3.7(2.4)$ & $5.6(3.1)$ & $8.8(2.0)$ & 6.35 & $<0.005$ \\
\hline
\end{tabular}

1. ANOVA degrees of freedom, $v_{1}=3, v_{2}=43$.

NS, no statistically significant association. 
and the physical stress the dialysis makes in terms of brain metabolism and toxic metabolites in general (Kemph, 1982).

Psychiatric morbidity in relation to the aetiology (Table 5) of the renal failure was reflected in significant differences on the anxiety and hysteria scales. Many variables may play role here, such as type of personality and its relation to susceptibility to physical illness (e.g. those with hypertenson scored more on anxiety), medication (e.g. antihypertensives), type of therapeutic procedure (e.g. surgery) and type of disability the patient has. All these variables need to be studied further.

\section{Acknowledgements}

The authors would like to thank Professor Tom Craig and Professor Simon Wessely for their comments and guidance on the original manuscript.

\section{References}

Aghanwa, H. S. \& Morakinyo, O. (1997) Psychiatric complications of hemodialysis at a kidney center in Nigeria. Journal of Psychosomatic Research, 42, 445-451.

Gurland H. J., Brunner, F. P., Chantler, C., et al (1975) Combined report on regular dialysis and transplantation in Europe. VI. Proceedings of the European Dialysis and Transplant Association, 12, 13-23.

Kemph, J. P. (1982) End-stage renal disease dialysis. Psychiatric Clinics of North America, 5, 407-417

Maghazaji, H. I., Alwash, R., Murtadah, M., et al (1982) Psychoneurotic profiles in Iraqi medical students. British Journal of Medical Psychology, 55, 271-274

Phipps, A. \& Turkington, D. (2001) Psychiatry in the renal unit. Advances in Psychiatric Treatment, 7, 426-432.

Racy, J. (1980) Somatization in Saudi women. A therapeutic challenge. British Journal of Psychiatry, 137, 212-216.

\title{
A 12-year follow-up of a sample of patients dependent upon heroin
}

\section{Saima Niaz, ${ }^{1}$ Nadia Arshad, ${ }^{2}$ Mariam Haroon, ${ }^{3}$ Fahd A. Cheema, ${ }^{4}$ Khalid A. Mufti ${ }^{5}$ and Haroon Rashid Chaudhry ${ }^{6}$}

\begin{abstract}
${ }^{1}$ Assistant Professor, Department of Psychiatry, Fatima Jinnah Medical College/Sir Ganga Ram Hospital, Lahore, Pakistan, email niazpsych@yahoo.com

${ }^{2}$ Deputy Manager Research, College of Physicians and Surgeons, Pakistan ${ }^{3}$ Medical Officer, Department of Psychiatry, Services Hospital, Lahore, Pakistan ${ }^{4}$ Medical Officer, Department of Psychiatry, Fatima Jinnah Medical College/Sir Ganga Ram Hospital, Lahore, Pakistan

${ }^{5}$ Medical Director, Ibadat Hospital, Peshawar, Pakistan ${ }^{6}$ Professor and Head, Department of Psychiatry, Fatima Jinnah Medical College/Sir Ganga Ram Hospital, Lahore, Pakistan
\end{abstract}

Hentan eroin addiction is a chronic, relapsing and remitting condition. Each year $2-5 \%$ of addicts discontinue drug use permanently and $1-2 \%$ die, mostly of overdose (Robins, 1993). A study of 129 opiate-addicted patients on a monthly maintenance regimen found that those with a family history of opium use had an earlier age at onset (Chaudhry et al, 1991). Long-term follow-up studies of people who misuse opiates have revealed that opioid dependence appears to run a chronic, relapsing and remitting course with a significant mortality (10-15\%) over 10 years (Robson, 1992). Metrebian et al (1998) reported that long-term heroin abstinence was associated with less criminality, psychological distress and morbidity; Hser et al (2001) reported it was associated with higher employment rates.

In another study, 78 opiate users were followed up after successful in-patient detoxification. Eleven categories of lapse precipitant were identified: cognitive, mood, external withdrawal, interpersonal, leaving a protected environment, drug availability, drug-related cues, craving, priming, and social pressures and young age (Bacchus et al, 2000). Substantial periods of employment and marriage are pointers to a good outcome (Zhang et al, 2003). Rasheed et al (1992) showed that earlier age at first consumption of the drug was associated with the misuser faring better on substitution programmes.

\section{Method}

This was a hospital-based, 12-year follow-up study. The sample comprised 137 male heroin-dependent patients, aged 20-40 years, admitted to the Free Psychiatric Clinic at Ahbab Hospital. The Clinic, run by grant from the community, has provided services for 22 years. It is located in the urban slums of Lahore. Written consent was obtained. The patients' mean age was 26.4 years at first assessment. Most patients (115) were inhaling heroin, but 22 were smoking it. A semi-structured interview (including demographic details), thin layer chromatography (TLC) and intranasal naloxone challenge tests were used as screening instruments. In the naloxone challenge, papillary response, pulse rate and blood pressure were measured, and TLC is useful for separating organic compounds.

The intervention did not comprise a comprehensive rehabilitation programme for the patients but there were regular educational programmes addressing the hazards of drug addiction during the stay. The average duration of treatment was 2 weeks. The special programmes addressing the hazards of drug addiction were arranged for patients and caregivers fortnightly for 3 months, and later monthly for 9 months (15 sessions in total), with the help of a local non-governmental organisation, Project for Environmental Protection, Antinarcotics Community Education (PEACE). 